\title{
Investigation and Research on Community Sports Public Service in Nanchang City
}

\author{
Hui Xiao \\ Jiangxi Science \& Technology Normal University, JiangXi Province, Nanchang, 330013
}

Keywords: Nanchang City; community sports; investigation and research

\begin{abstract}
Creating a good community sports public service is an important measure to promote national fitness, improve people's happiness index, and promote social harmony. The paper takes Nanchang community sports public service as the research object, and analyzes the problems of community sports public service in Nanchang City, including the incomplete and unbalanced community sports facilities, the outdated community sports facilities, and the lack of dedicated personnel management and guidance in community sports facilities, and community sports. The opening of the venue is not enough, and the reasons behind it are discussed. The community leaders neglect the construction of community sports public services, some real estate developers avoid community sports facilities, the management of community sports facilities is insufficient, and the investment source is relatively simple. Finally the development strategies of community sports public services in Nanchang City were expounded, to increase the sports propaganda of community residents, raise funds from various parties, increase the investment of community sports funds, diversify the development of community sports facilities, and increase the supervision of community sports facilities.
\end{abstract}

\section{Introduction}

With the development of society and the progress of the times, people pay more attention to physical exercise than ever before. The national fitness is a national strategic promotion facility. The quality of community sports public services greatly affects people's physical exercise. To this end, improving community sports public services is a key consideration for relevant departments.

\section{Status Quo of Community Sports Public Service Development in Nanchang City}

Nanchang City has jurisdiction over 6 districts and 3 counties, and also has a national new district - Qijiang New District. Since the reform and opening up, Nanchang's economy has developed rapidly, the city's appearance has changed with each passing day, and the quality of life of urban residents has also improved significantly. At the same time, the construction of community sports public services in Nanchang City has also been greatly improved during this period, but it is undeniable that there are still some shortcomings, such as lack of special personnel management and guidance in community sports facilities, and relatively old community sports facilities. The measures to improve the public service level of community sports in Nanchang City are very necessary.

\section{The Problems of Community Sports Public Services in Nanchang City}

\subsection{Incomplete and Unbalanced Configuration of Community Sports Facilities.}

Through interviews with several communities in Nanchang City, the distribution of sports facilities in several communities in Nanchang is not complete enough, and even some communities have no common sports facilities such as basketball courts and table tennis courts. Moreover, the distribution of community sports facilities in Nanchang City is uneven. The configuration of community sports facilities in An Yi County and Jinxian County, which are relatively backward in economy, is obviously behind the allocation of community sports facilities in Donghu District and 
Xihu District.

\subsection{Outdated Community Sports Facilities.}

At present, the existing sports facilities in many communities in Nanchang have been used for a long time, and the use function has dropped significantly. This situation is more serious in the communities of the old town. Many residents who like to exercise say that community sports facilities that are no longer working properly beyond the time limit should be replaced in time to prevent a safety incident. A resident of the Nanxun community mentioned that he was injured by an arm using aging sports machinery [1].

\subsection{Lack of Dedicated Personnel Management and Guidance in Community Sports Facilities.}

During the visit, when the problem community sports facilities were responsible for the care, many residents responded differently, and some residents even said that they did not know, who cares who manages. At present, many communities in Nanchang City do not have full-time sports executive management personnel. At the same time, when some communities cause relatively new sports equipment and do not arrange corresponding personnel to be responsible for guidance, people want to play these sports equipment but can't play because they don't know how to play.

\subsection{Insufficient Opening of Community Sports Venues.}

Through interviews, it was found that even though many communities in Nanchang have gymnasiums, swimming pools, gyms, etc., they usually only serve the personnel of the system and adopt closed management. This is undoubtedly not conducive to the fitness of the community residents.

\section{The Causes of Many Problems in Community Sports Public Services in Nanchang City}

Some community sports public services in Nanchang City are relatively backward, seriously affecting the fitness life of local community residents, and have close relationship with the leaders of the community. The sports concept of these community leaders is very weak, and they are not very concerned about the construction of public sports services in the community. As a result, many community sports jobs that should be done are not implemented as scheduled.

In recent years, some real estate developers intend to avoid the construction of community sports facilities in order to maximize profits. For example, the community sports facilities that should be delivered at the same time as the housing check-in time will be completed in the future, and then slowly disappeared. There are also some real estate developers who often use the staged construction method for real estate because of insufficient funds. They divide a large real estate into several relatively small-scale residential areas, so that real estate developers can implement sports in the sports community. Less cost.

Many communities in Nanchang are in a state of chaos in the construction, use and management of sports facilities. There are even many communities that are not equipped with relevant staff for care and management after the implementation of sports implementation. The performance of the free sports facilities is particularly evident. During the visit, it is often seen that some sports facilities in the community such as basketball hoops, ping pong tables, and fitness equipment are placed in the same place for damage due to damage, and some communities have turned the gym into a warehouse in the property department. Some communities have opened up parking lots that should be used for physical exercise.

The construction of community sports public services in Nanchang requires a lot of money, especially for some more expensive sports equipment. However, at present, the funds needed for the construction of community sports public services in Nanchang mainly come from financial allocations, which makes the construction of community sports public services in Nanchang have strong dependence on the relevant financial departments. Once the relevant financial departments are unable to make timely allocations or allocate funds less. It is bound to have a relatively significant impact on the construction of community sports public services. In accordance with the 
relevant provisions of the "People's Republic of China Sports Law", although the relevant financial departments of Nanchang City have gradually increased the capital investment in sports in Nanchang, it can be found through facts that relying solely on financial allocation is not enough.

\section{Development Strategy of Community Sports Public Service in Nanchang City}

\subsection{Increase the Intensity of Sports Promotion for Community Residents.}

In the process of improving the construction of community sports public services in Nanchang, the relevant departments must be very clear about the service targets of this work. To this end, it is necessary to increase the publicity of community residents' fitness, so that they can clarify the importance of fitness, so as to ensure that community sports facilities can be more fully utilized. There are many specific methods, such as setting up some cultural columns in the conspicuous position of the community, and expressing the importance of fitness in the form of words; in the community, regular sports events such as basketball games, running games, table tennis competitions, etc. are held regularly.

\subsection{Raise Funds from Multiple Parties to Increase Investment in Community Sports Funds.}

The low level of community sports public service in Nanchang City is largely due to the poor sports facilities. Some sports facilities that cannot be used normally beyond the time limit have not been repaired or replaced in time, and the main reason for this situation is insufficient funds. . To this end, the government financial department should first increase financial support for community sports and ensure that the community has sufficient funds for the construction of sports facilities. Secondly, community leaders should find ways to open up channels for capital introduction, such as mobilizing social groups and social enterprises for financial support or physical in-kind funding. At the same time, they can also mobilize residents of the community to raise funds for community sports development in a spontaneous manner. In addition, the community can also withdraw part of the funds from the property management fee for the construction of community sports facilities.

\subsection{Diversify Development of Community Sports Facilities.}

In order to better meet the needs of community residents, relevant departments should consider more in the selection of community sports facilities to ensure the diversity and comprehensiveness of community sports facilities. Only in this way can we better balance different groups of people such as the elderly and middle-aged the physical needs of people and young people. At the same time, the existence of disabled people in the community should also be considered, so they should also be equipped with corresponding sports facilities.

\subsection{Increase the Supervision of Community Sports Facilities.}

After the deployment of the community sports facilities, the relevant departments can not let it go, because doing so will greatly reduce the service life of sports facilities and affect the effectiveness of sports facilities. To this end, the relevant departments should arrange some personnel to be responsible for the supervision of community sports facilities, and timely repair the sports facilities that have not met the standards of use until they meet the standards of use, and replace those that cannot be repaired in time.

\section{References}

[1] Liu Jindan. Research on the Operation Mechanism of National Fitness Public Service in Nanchang City [D]. Jiangxi Normal University, 2017.

[2] Zhang Xiaohang, He genesis. Research on the Public Service Path of Urban Community Sports [J].Sports Culture Guide,2015(02):1-4.

[3] Chen Xinsheng,Chu Jijun,Wang Baozhu.Analysis of the Structure and Operation Mechanism of Urban Community Leisure Sports Public Service System[J].Journal of Beijing Sport 
University,2012,35(10):35-41.

[4] ZHENG Weimin, REN Baoguo, LIU Dexin. Exploration of the Supply of Public Service in Urban Community Sports in the New Era [J]. Sports and science, 2012, 33(01):87-91.

[5] Du Jinrong. Investigation and Research on the Status Quo of Community Sports Facilities in Nanchang City_ A Case Study of 8 New and Old Community [J]. Entrepreneur Day Underground Half-Monthly (Theoretical Edition), 2008(09): 254-255. 